\title{
CASE OF TUBERCULOUS PLEURO-PERICARDITIS. CULTIVATION OF THE BACILLI ON LOEFFLER'S SERUM DIRECT FROM THE LESIONS.
}

BY E. J. MCWEENEY, M.A., M.D. (R.U.I.) ; D.P.H ; M.R.C.P.I. ;

Professor of Pathology and Bacteriology in the Medical School of the Catholic University, Dublin;

Bacteriologist to the Local Government Board for Ireland.

[Read in the Section of Pathology, February 21, 1902.]

THE patient, T. E., male, aged fifty-five, was admitted into the Mater Misericordiæ Hospital with left pleural effusion. Clear serum to the amount of 74 ounces was evacuated by tapping. Dulness was afterwards noted in the left hypochondrium, but there were no gastric symptoms, and the dulness was looked upon as due to an enlarged spleen-a view which was confirmed on the autopsy.

The post-mortem findings were:-An emaciated male body; pericardium much thickened; its anterior [mediastinal] surface thickly coated with inflammatory lymph, beneath which were little islets of caseation, some of which went right through to the serous aspect, where they appeared beneath the serous membrane as little yellowish plaques, smaller than a split pea. Beneath the upper part of the pericardium, where it overlay the great vessels, were several small caseous glands. Heart.-On its anterior surface, corresponding to the tubercular plaques on the parietal pericardium, were a few very small, greyish granular masses seated on the epicardium and (microscopically) seen to be tubercles. They were evidently the result of inoculation by friction. The endocardium, valves, and myocardium seemed normal. Left Lung.-Upper lobe odematous, lower lobe collapsed and airless, the pleura covered with a very thick layer of reticular fibrin, enclosing small caseous points as big as a pin's head. Right Lung contained many patches of consolidation up to the size of hazel nuts, and, on section, presenting small whitish dots on a grey surface [tubercular broncho-pneumonia]. Elsewhere the 
parenchyma was air-containing, and the pleura was quite free. Spleen.-Much enlarged, weighed 22 ozs. ; surface covered with a distinct, though thin, exudate; consistency increased, sprinkled with cheesy areas as big as a split pea. Under the microscope these contained enormons numbers of tubercle bacilli, but not a giant cell or other trace of tubercular structure. Kidneys weighed together 12 ozs., consistency firm, capsule stripped with difficulty, leaving many small depressions corresponding to minute cysts in the cortex, which also presented small white areas, smaller than a pin's head, and microscopically consisting of caseous foci enclosing masses of tubercle bacilli so large as to be just visible to the naked eye in the stained and mounted preparation. Liver.-Weight 54 ozs. ; scrutiny of the cut surface with a hand-lense showed minute opaque clots, which proved microscopically to be similar to those in the kidney, and, like them, to contain tubercle bacilli in large numbers. Digestive Canal normal. Aorta extremely atheromatous ; at the convexity of the arch was a group of caseous superior pericardial lymphatics which seemed on the point of ulcerating through into the blood-stream.

Brain and Cord could not be examined.

This case is one of terminal generalised infection with large numbers of tubercle bacilli. The areas of necrosis are not tubercles, for they show no trace of tubercular structure, containing neither epithelioid nor giant cells. The reactive forces of the individual may have been too depressed, or the virulence of the bacilli or their number too great for the development of the usual tissue-changes. The case is a most striking example of the inverse ratio so often remarked between the "typicity" of tubercular structure and the number of bacilli. The source of the bacilli is in all probability to be looked for in a discharge of the caseous contents of some mediastinal gland into the blood-stream. The appearances at the aortic convexity are highly suggestive of a repetition of this process, prevented by the death of the patient. The caseous areas lay within a millimeter or two of the atheromatous intima, and this part of the vessel closely 
resembles the beautiful preparations shown by Prof. Benda at the London Tuberculosis Congress as illustrating intravascular tuberculosis. The condition of the pericardium was extremely interesting, and very similar to that in a case which he (the speaker) had shown at that Section last year. The caseous areas contained masses of bacilli quite visible to the unaided eye when the preparation was held up to the light. Since reading Osler's paper on the causation of pericarditis he had found that a much larger number of cases were of tubercular origin than was generally thought in this country to be the case. Careful examination was required to establish their true nature, and the tubercular nature of many casses had undoubtedly escaped observation.

The large number of bacilli present in this case made it a suitable one for cultivative experiments, and he had accordingly "skipped" the guinea-pig stage and started cultures on Loeffler's serum direct from the pericardium. About half the tubes inoculated yielded pure cultures of the tubercle bacillus, and exhibited extremely well the lichenoid growth and the tendency to spread on to the glass. From the serum he had transplanted on to glycerinated potato, and now showed :some very luxuriant growths, the bacillary serum being of a light reddish hue. It had spread on to the dilute glycerine below the constriction. Cultures of the third generation on glycerine-agar were succeeding well. In these the bacillary growth was whitish. From the standpoint of pathological anatomy and bacteriology he thought the case was worthy of being laid before the Section. 